\title{
Effect of Grain Size on Residual Loss of Mn-Zn Ferrites
}

\author{
K. Takadate, Y. Yamamoto, A. Makino \\ Central Laboratory (Nagaoka), Alps Electric Co. Ltd., \\ 1-3-5 Higashitakami, Nagaoka, Niigata 940, Japan.
}

\begin{abstract}
The effect of grain size on residual loss of $\mathrm{Mn}-\mathrm{Zn}$ ferrites was investigated. $\mathrm{Mn}-\mathrm{Zn}$ ferrites with grain size of 1.5 to $4.3 \mu \mathrm{m}$ were prepared by sintering a hydrothermally precipitated powder. The residual loss of the $\mathrm{Mn}-\mathrm{Zn}$ ferrites, which was computatively separated from the core loss, occupies the majority part of the core loss at $1 \mathrm{MHz}$ and is reduced with decreasing the grain size. The reduction of residual loss may be contributed to the decrease of a energy loss of damping for domain wall motion caused by subdivision of domain.
\end{abstract}

\section{I . INTRODUCTION}

$\mathrm{Mn}-\mathrm{Zn}$ ferrites have been extensively used for transformers utilized for switching power supplies because of the low core loss at high frequency However, if a high frequency driving up to the $\mathrm{MHz}$ range is needed, an increase of the core loss of $\mathrm{Mn}-\mathrm{Zn}$ ferrites will be a serious problem. The increase of the core loss in $\mathrm{MHz}$ range may be caused by an increase of the residual loss, which occupies the majority of the core loss of $\mathrm{Mn}-\mathrm{Zn}$ ferrites in $\mathrm{MHz}$ range[1]. Therefore the reduction of the residual loss is necessary for the applications of $\mathrm{Mn}-\mathrm{Zn}$ ferrites in $\mathrm{MHz}$ range. We have reported that $\mathrm{Mn}-\mathrm{Zn}$ ferrites with fine grain sizes under $3 \mu \mathrm{m}$ showed the low core loss on comparing with a conventional $\mathrm{Mn}-\mathrm{Zn}$ ferrite with grain size of $10 \mu \mathrm{m}$ at a frequency from 0.5 to $2 \mathrm{MHz}[2,3]$. In this paper the effect of grain size on residual loss of $\mathrm{Mn}$ $\mathrm{Zn}$ ferrites is investigated.

\section{II . EXPERIMENTAL}

$\mathrm{Mn} 0.72 \mathrm{Zn} 0.16 \mathrm{Fe} 2.12 \mathrm{O}_{4}$ ferrites with the grain size of 1.5 to $4.3 \mu \mathrm{m}$ were prepared by sintering a hydrothrmally precipitated ferrite powder. The grain size was changed by the sintering temperature of $1323 \mathrm{~K}$ to $1423 \mathrm{~K}$ and the amount of additive, 0 to $0.4 \mathrm{wt} \%$ of $\mathrm{Ta}_{2} \mathrm{O}_{5}$.

The core loss $(P \mathrm{cv})$ of the $\mathrm{Mn}-\mathrm{Zn}$ ferrites was computatively separated into three loss components, which were the magnetic loss $(P M)$, eddy current loss $(P e)$ and equivalent dielectric loss $(P \mathrm{~d})$ due to displacement current [1]. The analysis of Pcv was carried out by using the medium parameters; relative complex permeability at low frequency $\left(\mu r^{\prime}, \mu r^{\prime \prime}\right)$, dc conductivity $(\sigma)$, relative permetitivity (er) and conductivity for displacement current $(g)$ [1]. er and $g$ were determined by the frequency dependence of impedance of the ferrites. The hysteresis loss $(P \mathrm{~h})$ was determined by $P \mathrm{cv}$ at $1 \mathrm{kHz}$ because Pcv per cycle hardly varied under $10 \mathrm{kHz}$. The residual loss $(P \mathrm{r})$ was calculated as $P_{\mathbf{r}}=P_{M}-P \mathbf{h}$ assuming that $P \mathbf{h}$ is proportional to frequency.

The grain size was observed by SEM. Magnetic properties, which are $P c v$ and ( $\left.\mu r^{\prime}, \mu r^{\prime \prime}\right)$, and frequency dependence of impedance were measured with an ac B-H loop tracer and a LCR meter respectively. $\sigma$ was measured by four-point probe method. All measurements were carried out at room temperature.

\section{III . RESULTS AND DISCUSSION}

A. Grain size and electric and magnetic properties

Figure 1 shows the change in the grain size as a function of $\mathrm{Ta}_{2} \mathrm{O}_{5}$ content. The grain size decreases from $4.3 \mu \mathrm{m}$ to $1.5 \mu \mathrm{m}$ with decrease of the sintering temperature and increase of the $\mathrm{Ta}_{2} \mathrm{O}_{s}$ content.

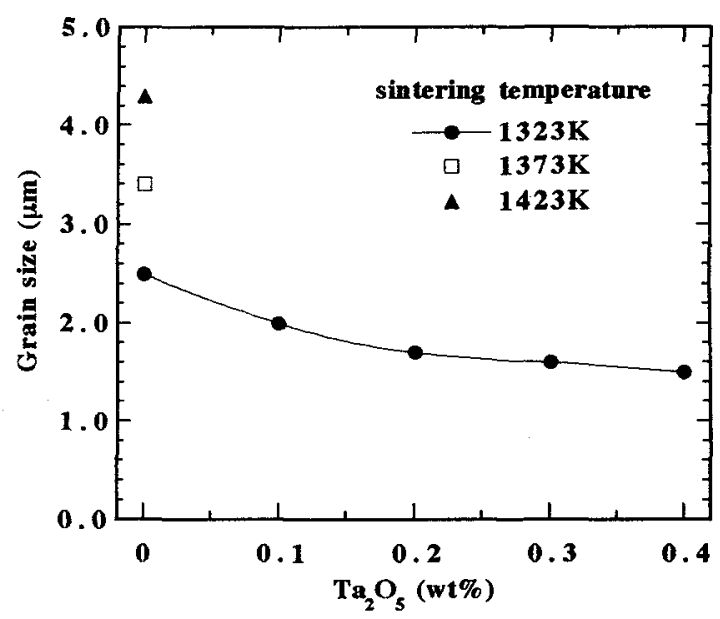

Fig. 1 Change in the grain size as a function of $\mathrm{Ta}_{2} \mathrm{O}_{5}$ content. The samples of $0 \mathrm{wt} \% \mathrm{Ta}_{2} \mathrm{O}_{5}$ were sintered at different temperature of 1323 to $1423 \mathrm{~K}$. Other samples were sintered at $1323 \mathrm{~K}$.

The electric and magnetic properties are shown in table1. These properties were used for the analysis of $P \mathrm{cv}$. 
Table 1 Electric and magnetic Properties

\begin{tabular}{cccccc}
\hline $\begin{array}{c}\text { Sintering } \\
\text { temperature }\end{array}$ & $\begin{array}{c}\text { TazOs } \\
(\mathrm{wt} . \%)\end{array}$ & $\begin{array}{c}\mu \mathrm{r}^{\prime}+\mathrm{j} \mu \mathrm{r}^{\prime \prime} \\
\text { at } 1 \mathrm{kHz}\end{array}$ & $\begin{array}{c}\sigma \\
(\mathrm{S} / \mathrm{m})\end{array}$ & er & $\begin{array}{c}g \\
(\mathrm{~S} / \mathrm{m})\end{array}$ \\
\hline $1323 \mathrm{~K}$ & 0 & $2100+\mathrm{j} 157$ & 13.9 & 35000 & 56 \\
$1323 \mathrm{~K}$ & 0.1 & $1680+\mathrm{j} 73$ & 1.91 & 30000 & 60 \\
$1323 \mathrm{~K}$ & 0.2 & $1410+\mathrm{j} 63$ & 1.36 & 27000 & 63 \\
$1323 \mathrm{~K}$ & 0.3 & $1180+\mathrm{j} 51$ & 1.77 & 24000 & 68 \\
$1323 \mathrm{~K}$ & 0.4 & $990+\mathrm{j} 52$ & 2.37 & 27000 & 60 \\
$1373 \mathrm{~K}$ & 0 & $2550+\mathrm{j} 142$ & 13.4 & 44000 & 70 \\
$1423 \mathrm{~K}$ & 0 & $2730+\mathrm{j} 375$ & 7.90 & 61000 & 68 \\
\hline
\end{tabular}

\section{B. Grain size dependence of residual loss}

The analysis of $P c v$ was carried out to discuss the grain size dependence of the residual loss. $P \mathrm{cv}$ was separated into four loss components described in section II. Figure 2 and figure 3 show the change in the loss components at $1 \mathrm{MHz}$ as a function of sintering temperature and the $\mathrm{Ta}_{2} \mathrm{O}_{5}$ content respectively. Pr occupies the majority of more than $50 \%$ of $\mathrm{Pcv}$ at $1 \mathrm{MHz}$ in both figures. Pr is reduced with decreasing the sintering temperature and increasing the $\mathrm{Ta}_{2} \mathrm{O}_{5}$ content. The $\mathrm{Ta}_{2} \mathrm{O}_{5}$ content dependence of $\mathrm{Pr}$ is similar to that of the grain sizes. Figure 4 shows the grain size dependence of $P \mathrm{cv}$ and $P r . P r$ is reduced with decreasing the grain size. The relationship between $P r$ and grain size indicates that fine grain size is effective in reducing $P$ r. $P$ cv varies discontinuously at a grain size of $2.5 \mu \mathrm{m}$ reflecting the decrease of $P \mathrm{~h}$ and $P \mathrm{e}$ by an addition of $0.1 \mathrm{wt} \% \mathrm{Ta}_{2} \mathrm{O}_{5}$. And $P \mathrm{cv}$ shows the minimum value at a grain size of $2 \mu \mathrm{m}$. This is contributed to the increase of $P \mathrm{~h}$ with the increase of $\mathrm{Ta}_{2} \mathrm{O}_{s}$ content and the reduction of $P \mathbf{r}$ with the decrease of the grain size.

The origin of $P r$ has been investigated from a domain

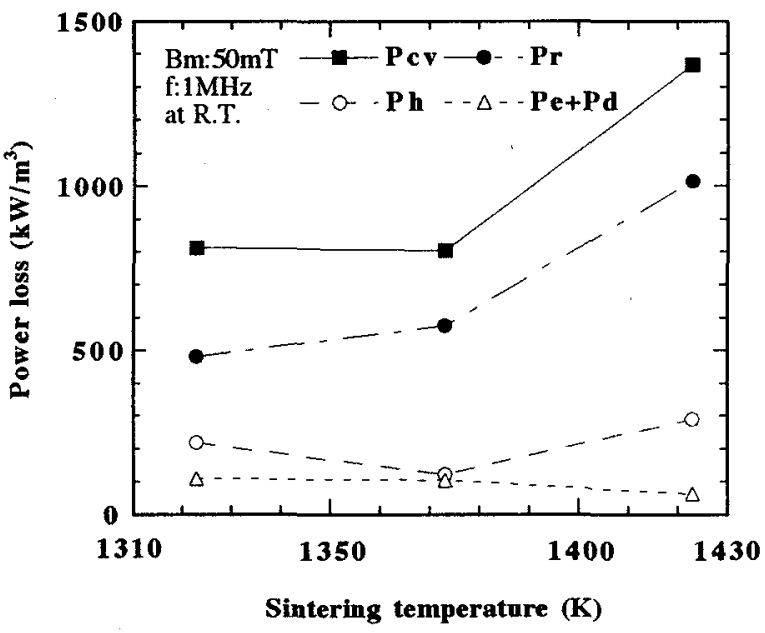

Fig.2 Change of each loss component at $1 \mathrm{MHz}$ as a function of sintering temperature in $0 \mathrm{wt} \% \mathrm{Ta}_{2} \mathrm{O}_{5}$ samples. $P \mathrm{~d}$ is included in $P$ e because $P$ d occupies at most $0.2 \%$ of $P \mathrm{cv}$ at $1 \mathrm{MHz}$

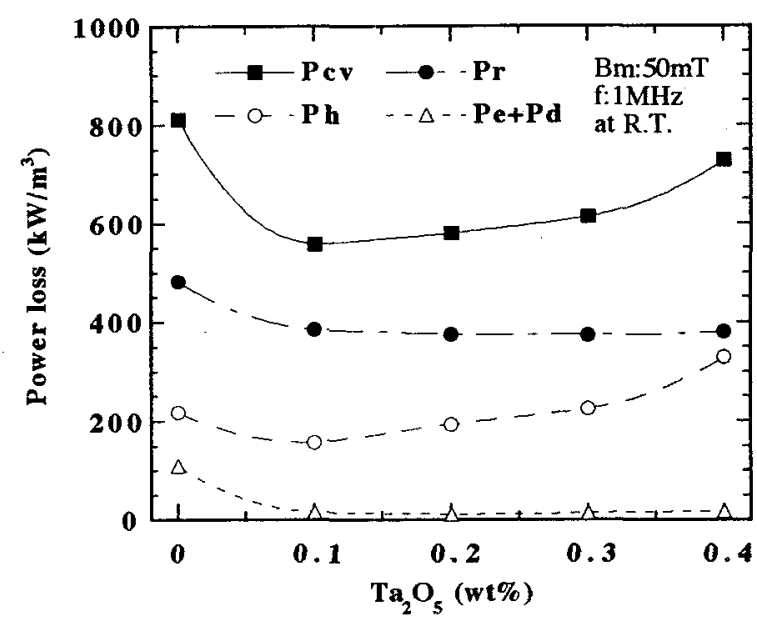

Fig.3 Change of each loss component at $1 \mathrm{MHz}$ as a function of $\mathrm{Ta}_{2} \mathrm{O}_{3}$ content for the samples sintered at $1323 \mathrm{~K} . P \mathrm{~d}$ is included in Pe the same as Fig.2.

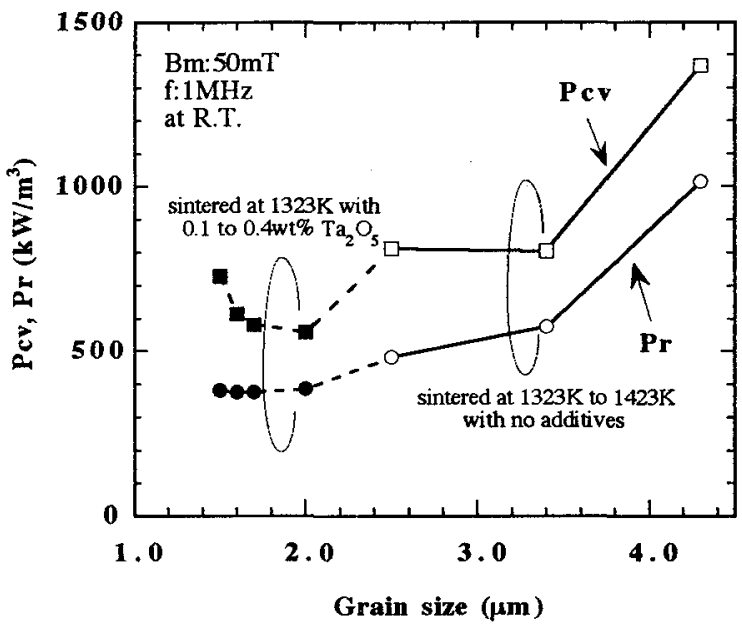

Fig.4 Grain size dependence of $P c v$ and $P r$ for the samples. prepared on several conditions.

wall motion[1,4]. The reduction of $P r$ is associated with the change of domain structure depending on the grain size. It is known that the domain of ferrites is subdivided with decreasing the grain size[5]. With the decrease of domain size, the number of domain wall per volume increases; therefore the amplitude of vibration in domain wall motion is reduced in the same $B \mathrm{~m}$ and driving frequency. In other words, the switching frequency of spin inside the domain wall $(f s)$ is reduced. On the other hand, a energy loss of damping for damain wall motion is proportional to $\mathrm{s}^{2}$. Consequently the reduction of Pr may be related to the decrease of a energy loss of damping for damain wall motion caused by subdivision of domain.

\section{IV . CONCLUSIONS}


The effect of grain size on residual loss for the Mn-Zn ferrites was investigated. The following results were obtained:

1. The residual loss occupies more than $50 \%$ of the core loss of the $\mathrm{Mn}-\mathrm{Zn}$ ferrites at $1 \mathrm{MHz}$.

2. The residual loss is reduced with decreasing the grain size.

3. The reduction of residual loss may be contributed to subdivision of domain caused by decreasing the grain size.

\section{REFERENCES}

[1]H. Saotome, Y. Sakaki, IEEE Trans. Magn.,Vol. 33[1], pp.728 - 734, 1997.

[2]Y. Yamamoto, A. Makino, J. Magn. Magn. Mater. 133, pp.500 - 503, 1994.

[3]A. Makino, Y. Yamamoto, New Horizons for Materials, techna Srl, pp.361 - 368, 1995.

[4]S. Yamada, E. Otsuki, J. Appl. Phys., Vol. 81[8], pp.4791 - 4793, 1997.

[5]P. J. van der Zaag, A. Noordermeer, J. J. M. Ruigrok, P. T. Por, M. Th. Rekveldt, D. M. Donnet, J. N. Chapman, Proc. ICF-6, pp. 819 - 822, 1992. 